\title{
Brinquedos do Carnaval Pernambucano: Um "Campo de Lutas" Cultural entre Maracatu Rural e Ursos na Perspectiva da Construção Social Bourdiesiana
}

\section{Toys of the Carnival of Pernambuco: A "field of struggles" Maracatu Rural Cultural and bears in the perspective of Social construction Bourdiesiana}

\author{
Roberta de Albuquerque Pereira (PEREIRA, R. de A.) ${ }^{*}$
}

RESUMO - Inseridos em um cenário onde as relações de produção e trocas orientam a vida social contemporânea, vive-se, constantemente, disputando espaço e reconhecimento. No que diz respeito a cultura, essa perspectiva não é diferente, estando-se inseridos em uma lógica mercantil, que levam as pessoas a buscar distinção por meio de uma dinâmica de poder. Nesse sentido, a fim de conhecer com maior profundidade as características desse fenômeno, no presente artigo ${ }^{1}$ se propõe a analisar como estava ocorrendo o processo de distinção entre Maracatu Rural e Ursos, através de uma análise comparativa entre estes, para identificar o que levaria um brinquedo a ser mais reconhecido que outro. Para dar suporte a compreensão desse fenômeno, utilizouse a teoria Sociológica Econômica de Pierre Bourdieu (2001), uma vez que possibilita entender a estrutura da sociedade dentro de uma dinâmica econômica. O problema de pesquisa é de cunho qualitativo, com caráter interpretativista e etnográfico. Como resultado, identificou-se a distinção do Maracatu Rural sobre os Ursos devido as influências políticas, sociais, econômicas e simbólicas. Esta pesquisa foi realizada no carnaval de 2013 e 2014, das cidades do Recife (PE), Nazaré da Mata (PE) e Aliança (PE).

Palavras-chave: Turismo; Poder; Distinção; Produto Cultural; Maracatu Rural; Ursos.

ABSTRACT - Inserted in a scenario where the relations of production and the contemporary social life, lives, constantly vying for space and recognition. With regard to culture, this perspective is no different, and inserted in a market logic, leading people to seek distinction by means of a dynamic power. Accordingly, in order to know in greater depth the characteristics of this phenomenon, this article aims to analyze how was the process of distinguishing between Rural Maracatu and bears, through a comparative analysis between these, to identify what would take a toy to be more recognized than the other. To support the understanding of this phenomenon, the sociological theory of Pierre Bourdieu (2001) since it makes it possible to understand the structure of society in a dynamic economy. The problem is of qualitative nature, with interpretativista and ethnographic character. As a result, identified the Maracatu Rural distinction about the bears due to political influence, social, economic and

\footnotetext{
* Formação: Graduação em Administração pela Universidade Federal de Pernambuco (UFPE) e em Gestão de Turismo pelo Instituto Federal de Ciências e Tecnologia de Pernambuco (IFPE). Mestrado em Administração em Marketing pelo Programa de Pós-Graduação em Administração (PROPAD/UFPE). Atividade profissional: Pesquisadora e Professora na Faculdade Joaquim Nabuco Olinda. Endereço físico para correspondência: Rua Joaquim Teixeira, n. 156. CEP: 52280-130 - Recife/PE - Brasil. E-mail: robertapropad@gmail.com ${ }^{1}$ Versão preliminar apresentada deste artigo foi apresentada no Seminário da Associação Nacional de
Pesquisa e Pós-Graduação em Turismo - ANPTUR 2016.
} 
symbolic. This research was carried out in 2013 and 2014, Carnival of the cities of Recife (PE), Nazaré da Mata (PE) and Alliance (PE).

Key words: Tourism; Power; Distinction; Cultural Product; Maracatu Rural; Bears. 


\section{INTRODUÇÃO}

Pernambuco, segundo a EMPETUR - Empresa de Turismo de Pernambuco (2013), é um Estado marcado pela diversidade cultural, conhecido como cenário cultural vivo, graças às contribuições que, segundo Shinohara et al. (2013), advieram dos povos que povoaram o Estado, como portugueses, holandeses, judeus etc. De acordo com Grillo (2011), o solo fértil em expressões culturais permite o reconhecimento do Estado, em nível nacional e internacional, e encanta por sua diversidade, representada no seu patrimônio cultural, material e imaterial.

Uma das principais atividades econômicas do Estado, segundo a Empetur (2013) está relacionada ao turismo. Atividade responsável por gerar emprego e renda para o Estado, assim como, movimentar a economia local durante todo o ano com os eventos populares como Carnaval, Semana Santa e São João.

No carnaval, festa popular do Estado, segundo a Empetur (2013), se pode apreciar diversos brinquedos (entende-se como brinquedo, o meio de diversão das pessoas. São as crenças traduzidas em danças, ritmos e performances), como Maracatus, Caboclinhos, Coco de Roda, Ursos e o Frevo; já no interior se conta com os Caretas de Triunfo, Caiporas de Pesqueira e Papangus de Bezerros. Cada brinquedo possuindo uma relevância e significação para sua região. Entretanto, à medida que os brinquedos vão sendo reconhecidos por admiradores e brincantes, também vão se destacando em relação aos demais. Dentre os diversos brinquedos populares integrantes da cultura pernambucana, assume-se que os acima citados, fazem parte do contexto maior contido na cultura do carnaval. Partindo de observações e conhecimentos prévios, percebeu-se que uns brinquedos têm maior reconhecimento do público do que outros. Dessa forma, verificou-se haver uma distinção entre os folguedos (brinquedos populares), ou seja, alguns se tornaram mais populares que outros, fenômeno que parece estar baseado nas relações de poder que são articuladas pelos diversos agentes que integram o mercado do entretenimento. Essas relações de poder envolvem diretamente três grupos distintos, quais sejam, os grupos propriamente ditos (brinquedos populares), os agentes internos (pessoas que pertencem aos brinquedos) assim como, os agentes externos (pessoas/entidades que os influenciam de alguma forma, como por exemplo, a Federação Carnavalesca de Pernambuco que segundo Pereira (2013), é responsável por 
autorizar ou não a apresentação dos grupos no concurso do carnaval). Esses grupos, a partir de seu ufanismo, determinarão cada brinquedo que se destacará dos demais no cenário do carnaval. Esse ufanismo pode aflorar a partir desses grupos de diversas maneiras seja pela admiração, adoração, identificação, ou por suas belezas, histórias e riquezas.

Como aporte teórico para entender como se dava essa relação de superioridade de um brinquedo para com outro, mediado pelo sentimento de ufanismo em demasia, utilizou-se da teoria de Bourdieu (2012), que fornece elementos para entender melhor como se dá essa prática, uma vez que se fundamenta na maneira como as relações sociais, se estruturam e são estruturadas por meio das leis do campo econômico. Bourdieu (2012) fornece subsídios para entender essa dinâmica econômica, a partir dos conceitos de campo e habitus que serão apresentados adiante.

A análise das relações entre os agentes envolvidos na lógica econômica que estabelece as regras no contexto da cultura do carnaval possibilita entender melhor os elementos que definem que um brinquedo se distingue dos demais (principalmente em relação a questão do patrocínio como influente na distinção do brinquedo, uma vez que o patrocínio é responsável pela divulgação e possibilidade de tornar popular e conhecido o brinquedo). Bourdieu (2011) apresenta esse tipo de mercado como um "campo de lutas" baseado em uma construção social. Uma das pesquisadoras observou essa luta por distinção de forma contundente, quando assistia ao concurso do carnaval do Recife. O "Maracatu Rural” (brincadeira típica da zona da mata de Pernambuco que consiste na disputa entre tribos indígenas pelo poder) se destacava mais em relação aos "Ursos do Carnaval" (brincadeira originária da cultura cigana e consiste na figura de um domador que segura um urso por uma corrente fazendo com que este dance em prol de dinheiro). Nesse sentido, considerou-se tornar-se importante compreender porque e como se dava esse processo de diferenciação entre esses dois brinquedos, na medida em que ambos são considerados patrimônios culturais, de acordo com a Empresa de Turismo de Pernambuco que, em tese, não apresentam uma hierarquia em termos de valor ou qualidade como produto cultural.

Tal fato levou a refletir como os agentes internos e externos elevavam um brinquedo popular à posição de distinção no mercado do entretenimento, valorizando mais um folguedo popular em relação a outros e quais os fatores que ocasionavam tal 
atitude. Se por um lado têm-se as influências de poder inerente aos agentes reguladores, por outro, tem-se um afastamento em relação aos outros brinquedos devido ao ufanismo advindo dos agentes envolvidos.

Como justificativas para realização desta pesquisa apontou-se inicialmente para os agentes envolvidos com os brinquedos populares que proporcionaram entender o funcionamento das posições e disposições na construção social deste campo de culturas populares, permitindo a compreensão da relevância dessas manifestações culturais e as formas de distinção de um brinquedo em relação a outro.

Acrescentam-se ainda as contribuições ofertadas neste estudo para a construção de uma visão crítica sobre a lógica econômica contemporânea, que analisa as questões de trocas não apenas pelo capital econômico, mas considerando questões intrínsecas ao indivíduo (capitais social, cultural e simbólico) adquiridas ao longo de sua trajetória de vida. Nesse sentido, os brinquedos populares contribuem para se analisar o processo de distinção cultural entre os mesmos, onde levam a refletir porque uns brinquedos se sobressaiam em relação a outros.

Para tratar do tema proposto, o presente artigo está estruturado da seguinte forma: Revisão de literatura, teoria utilizada, procedimentos metodológicos, análise de dados e, por fim, considerações finais.

\section{REVISÃO DE LITERATURA: UM CELEIRO CULTURAL}

Para melhor entender os objetos estudados, nesta seção são apresentados os dois brinquedos, de forma isolada, para o melhor conhecimento acerca dos mesmos.

Para entender o Maracatu Rural se considerou ser interessante retroceder em um contexto histórico, buscando conhecer o ambiente social, cultural e econômico em que estava inserido para entender o surgimento da tradição desta brincadeira.

De acordo com Silva (2008), o Brasil, no período colonial foi dividido em capitanias, pelo Rei de Portugal, e foram doadas para alguns de seus amigos e conhecidos, como forma de garantir sua herança. Tendo Pernambuco como a capitania mais promissora, apresentava a cultura do açúcar como principal atividade econômica. 
A forma enérgica e autoritária com que a cultura do açúcar foi introduzida nas colônias, acarretou em problemas sociais, como a destruição ou desalojamento de sociedades humanas devido a não adequação ao sistema, tendo em vista que se tratava de pessoas com técnicas rudimentares para desempenhar atividades de subsistência (SILVA, S., 2008).

Outro povo que também fez história em território pernambucano foram os índios. História marcada por lutas territoriais e de identidade. De acordo com Silva (2006), as aldeias indígenas serviam de reserva de mão de obra, além de recrutamento para combater possíveis conflitos, entre os portugueses e os negros. $\mathrm{O}$ autor enfatiza que em decorrência das invasões nas terras e extinção dos aldeamentos, alguns povos migraram para outras comunidades, onde trabalhavam com o cultivo sazonal da cana de açúcar, na zona da mata do Estado.

É nesse contexto que surgem os maracatus, que congregam personagens e histórias que estão ligadas a cultura canavieira. Silva (2012) apresenta a composição da organização estrutural do Maracatu Rural formada pelos seguintes personagens: o Mateu, a Catirina (ou Catita) e a Burra: personagens responsáveis por avisar ao resto do grupo se o caminho está livre para sua passagem, assim como, roubar comidas para alimentar os demais integrantes do maracatu; Silva (2012) afirma ainda que o Portaestandarte: é o responsável por segurar a bandeira com o nome, a data da fundação e o símbolo do maracatu. E este folgazão deve ser ágil e hábil para não deixar nenhum outro grupo roubá-lo.

Segundo Lima (2013) a versão mais antiga para bandeira estava vinculada ao pote onde os dinheiros arrecadados eram depositados; Arreiamá: tem a função de proteger a corte real, a dama do paço e as baianas; Dama do Paço: responsável por carregar a calunga (boneca que protege o maracatu). De acordo com O Estadão de São Paulo (2010), a corte real: é composta pelo rei e a rainha; o mestre que comanda a brincadeira usando um apito e uma bengala na condução do grupo Ainda, segundo o autor, Os caboclos de lança: são personagens que protegem todos os brincantes do maracatu, assim como, abrem passagem para o mesmo desfilar, sendo de responsabilidade destes não permitir que outros brincantes roubem ou invadam seus grupos. 
Essa brincadeira, de acordo com Barachinha (2013), é tradicionalmente da cultura canavieira e a princípio consistia na disputa por relações de poder entre grupos do mesmo município e/ou circunvizinhos que brigavam em busca de prestígios diante dos demais grupos da região. Lima (2013) afirma que a brincadeira consistia num passeio pelos vilarejos dos canaviais onde os folgazões passavam pedindo dinheiro para os moradores, a fim de comprar bebidas. Brigas eram observadas frequentemente, porque os grupos tentavam roubar uns aos outros para comprar bebidas. Lima (2013) afirma também, que a brincadeira era completamente machista, devido ao caráter violento que a mesma apresentava.

Por outro lado, Lóssio e Pereira (2008) apresentam o brinquedo, Ursos do Carnaval, na sua estrutura física como um conjunto de figuras vestidas de "urso" homens que usam máscaras de urso, confeccionadas com papel machê e pintadas de várias cores; vestem macacão de estopa, veludo e pelúcia - junto a um "domador" que segura o "urso" por uma corda, além da figura do caçador. Quanto à performance, os autores comentam que $\mathrm{O}$ Urso se apresenta dançando embalado ao som da orquestra (sanfona, triângulo e bombo) e simula ataques ao público. Tendo a figura do domador segurando o bicho pelas correntes e o papel do caçador que porta uma espingarda, exibe o urso capturado. Geralmente estes personagens são acompanhados por balizas, cordão feminino e estandarte.

Os Ursos do Carnaval, segundo a Fundação Joaquim Nabuco (2014), têm origem nos ciganos da Europa que andavam pelas ruas da cidade, segurando animais presos em correntes, passando de porta em porta pedindo dinheiro, em troca, ordenavam que os animais dançassem. Afirma também, que a "La Ursa" como é conhecida popularmente, a brincadeira, está relacionada a imagem de crianças brincando nas ruas durante o carnaval, batendo latas, puxando alguém fantasiado de Urso gritando: “A La Ursa quer dinheiro, quem não dá é pirangueiro".

Assim como o Maracatu Rural, o Urso também participa do concurso do Carnaval do Recife, entretanto, a visibilidade e reconhecimento entre os dois ocorrem de forma diferente, observou-se na programação do Carnaval do Recife (2014), o número de grupos de Maracatu Rural que se inscrevem no concurso do Recife é maior que os demais brinquedos, por exemplo. Com base nesta observação, as relações de poder são responsáveis pelo direcionamento desta pesquisa, na qual utilizou-se da 
sociologia econômica de Bourdieu (2001) para explicar como se dava esse movimento dentro do brinquedo e a forma como se portava em relação às dinâmicas de poder que o cerca.

\section{TEORIA CAPITAIS E DISTINÇÃO: ATRIBUTOS CONSTITUINTES DO CENÁRIO DO CARNAVAL}

Bourdieu 2012 apresenta, em sua teoria social, a sociedade como estrutura estruturante de um sistema. Seguindo a lógica de mercadorização da cultura, buscou-se entender como esta estrutura estava ocorrendo dentro de uma dinâmica econômica. Sendo assim, fundamentou-se este artigo, na Sociologia Econômica de Bourdieu (2001), que segundo Garcia-Parpet (2013), apresenta questionamentos sobre os conceitos da teoria neoclássica da estrutura social econômica, decorrente de pesquisas realizadas em sociedades que conservavam tradições com economias diferentes da capitalista. Bourdieu (2000) aponta que essas pesquisas o levaram a refletir e perceber o quanto essa lógica mercantil é imposta, muitas vezes de forma brutal, nas sociedades que agem naturalmente dentro desta lógica incorporada nas práticas sociais. Garcia-Parpet (2006) corrobora afirmando que Bourdieu (2001), refutava a forma particular e etnocêntrica da teoria econômica, que se apresenta disfarçada em universalismo, levando os agentes a aceitá-la como sem pensar, por exemplo, em questões culturais.

Bourdieu (2001) ressalta na teoria econômica o conceito de capital simbólico e afirma que o poder simbólico é essencial para a sociedade moderna, chegando à conclusão que a lógica da economia de mercados é uma lógica simbólica, onde as verdades são transformadas em dominação. Wacquant (2002) afirma que essa dominação, seja de caráter pessoal ou estrutural, é responsável pela constituição do espaço social e o poder simbólico consiste na habilidade de transformar a realidade social por meio das representações. Hall (1997) ratifica, afirmando que é por meio do reconhecimento de significados identitários que as práticas sociais são regulamentadas.

O autor da teoria, Bourdieu (2001), assume este poder simbólico como um poder de construção da realidade que estabelece uma ordem e um sentido imediato de mundo, funciona como um instrumento de dominação, servindo de base para construção de uma 
ideologia constitutiva de um produto coletivo, servindo a interesses particulares e sendo passada a imagem de um interesse universal.

A construção do universo simbólico não deve ser enxergada como um lugar físico, mas como as diferentes formas de ocupações do sujeito que permitirá entender como ocorre o poder exercido pelos indivíduos, passiva ou ativamente diante essas relações (MOM, 2013). Bourdieu (2011) afirma que as posições ocupadas pelos indivíduos ou grupos nessa estrutura, não pode ser definida apenas como um ponto estático, onde ele assume uma posição relativa de superioridade ou inferioridade, mas deve-se analisar o sentido do seu trajeto social, podendo indivíduos de classes sociais distintas possuírem propriedades comuns nessa trajetória, ou seja, desfrutar de experiências comuns. Diante disso, o autor afirma que os agentes e os grupos de agentes são definidos pelas posições relativas que ocupam, podendo se encontrar em classes com posições vizinhas.

A inquietação proposta por Bourdieu (2000) à teoria econômica decorre do fato desta ser baseada em um habitus econômico particular, pensada em um determinado período histórico, e generalizada para todo o sistema econômico, sem ao menos pensar nas questões sociais, históricas e políticas que envolvem os agentes. Raud (2007) afirma que as ações econômicas deveriam ser analisadas por meio da sociologia, uma vez que esta traria uma visão econômica como subconjunto da sociedade.

Outro ponto abordado por Bourdieu (2000), diz respeito à importância e influência do agente político na construção do campo econômico. Segundo Raud (2007), o sociólogo afirma que a atuação e tradição do Estado são responsáveis pela construção das sociedades, e por determinar as regras de funcionamento do campo econômico, através de infraestrutura jurídica e regulamentos gerais. Para Bourdieu (2000), o Estado é responsável por promover disputas entre empresas, criar demanda e oferta, permitir entrada de novas organizações e influenciar as relações de poder entre os agentes do campo econômico. Diante do exposto, Bourdieu (2011) se recusa a analisar o campo econômico, apenas pelo acúmulo de capital econômico, mas como o sociólogo ratifica que o campo é construído socialmente, essa análise da relação de poder, deve ser observada através dos capitais (cultural, social e simbólico) adquiridos pelos agentes envolvidos no campo, onde não se devem negligenciar questões políticas e históricas. 
Os diferentes campos só possuem sentido através dos relacionamentos por meio dos jogos das oposições e distinções formando o que Bourdieu (2012) chamou de espaços sociais. Essas relações, ainda de acordo com Bourdieu (2012), objetivam a dominação dos agentes desprovidos de ascensão social no campo, por meio das normas a que eles são submetidos. Para o autor, as lutas pelos interesses dos agentes reduzem a identidade social das pessoas, transformando ou conservando as manifestações simbólicas.

Bourdieu (2012) argumenta que os dominados, em maioria, desprovidos de consciência, tornam-se pessoas submissas, escassos de cultura e de linguagem determinada pelas classes dominantes, ressalta ainda, que esses espaços, decorrentes da influência de agentes dominantes, conseguem se isolar ao meio externo, permitindo uma maior conexão e articulações entre eles, por meio das fronteiras estabelecidas pelos fatores culturais, econômicos, sociais e políticos. Segundo Gay e Pryke (2002), não há como pensar nas questões culturais, separadas das questões econômicas. Para os autores, a cultura está em todo lugar e as questões culturais são regidas por significados. Estes por sua vez, são desenvolvidos por ferramentas que darão sentido as práticas materiais, sejam elas econômicas ou culturais.

Wacquant (2002) assume que o espaço social está organizado pelo imbricamento entre o capital cultural e econômico, onde constituem motivos de conflitos sociais. $\mathrm{O}$ acúmulo desses capitais constitui os efeitos de uma dominação. Para Wacquant (2002) o objetivo, nesse caso, é se apropriar de uma identidade legítima e afirmá-la oficial e reconhecida, e caso seja necessário, enquadrá-la num mercado de bens simbólicos com regras e práticas próprias em busca de distinção. Entretanto, ao serem constituídos socialmente, estes bens devem ser modelados através de convenções sociais (MAUSS, 2002), para atender uma lógica de mercado, no caso, a Indústria Cultural.

A questão ideológica é trazida por Bourdieu (2012) como um sentido dado à vida, de forma que proporcione a condição de existência humana. Baudrillard (2005) afirma que essa ideologia é consumida pelos indivíduos não pela materialidade dos objetos ou pela utilidade dos mesmos, mas pelo valor simbólico que representam. Retondar (2007) corrobora ao afirmar que o mercado passou a integrar posições de lideranças na sociedade, não apenas por fomentar novas relações de produção, mas por expandir uma lógica mercantil em outros campos sociais, ampliando dessa forma, o 
universo cultural para práticas significativas como linguagem, arte, publicidade, onde constituem um campo complexo e extenso.

Por fim, Bourdieu (2005) apresenta que as relações de trocas monetárias pertencentes ao mercado econômico hoje, ocorrem apenas pela ótica do capital econômico, negligenciando questões importantes, como fatores históricos, culturais e políticos. Acredita também que a construção do campo econômico ocorre por meio de lutas, na busca pela dominação de uma classe e que este controle é decorrente do acúmulo de capitais, e do desenvolvimento da produção de bens simbólicos, segundo Bourdieu (2011) ocorre em paralelo ao processo de diferenciação que se dá pela diversidade de público e produtos, onde através de interpretações individuais, os produtos têm significados diferentes, seja na forma de valor cultural ou mercantil. Quando um produto de arte é significado através de valores mercantis, o autor acredita que surge uma nova categoria de bens simbólicos, onde no mercado, a arte pode ser considerada simplesmente uma mercadoria ou arte como pura significação. Fato contundente a esse processo de distinção e influência nas relações é possível decorrente ao que Bourdieu (2011) chama de capital, sendo este considerado toda forma de acúmulo de riqueza, seja ela cultural, social, econômica e simbólica.

Pode-se então entender o capital econômico, segundo Bonamino, Alves e Franco (2010) como o capital que se apresenta nas formas de produção (terras, fábricas e trabalho) e bens econômicos (dinheiro, patrimônio, bens materiais); por capital social, o conjunto de relações sociais que um indivíduo possui (BONNEWITZ, 2003); a respeito do capital cultural segundo Bonamino, Alves e Franco (2010), apresenta-se na forma de bens culturais (esculturas, livros, pinturas) e investimento acadêmico; e por fim, $o$ capital simbólico que Bonamino, Alves e Franco (2010) trazem como definição, o conjunto de rituais relacionados à honra e ao reconhecimento. Através deste capital é possível reconhecer que regras de boa conduta e protocolos não estão limitadas ao controle social, mas às vantagens sociais.

Partindo do pressuposto que o acúmulo dos capitais se dá por meio das vantagens sociais, ratifica-se então, a proposta levantada inicialmente, sobre o prestígio do Maracatu Rural em relação aos Ursos. Alguns pontos que tornam a indagação mais contundente serão apresentados adiante na análise dos dados. 


\section{PROCEDIMENTOS METODOLÓGICOS}

Dentro da seara de métodos pertencentes à abordagem qualitativa, se propôs a utilizar na pesquisa um estudo de caráter etnográfico. Este método alinha-se à Sociologia Interacional, uma vez que esta se relaciona com a busca do entendimento dos significados e dos discursos a partir de pistas advindas de interações sociais (GOFFMAN, 1964). Essas pistas constroem cenários e dão significados às interações face a face, uma vez que, os detalhes constituintes da linguagem pragmática permitem uma compreensão não apenas no nível da semântica, mas no tocante ao contexto (RIBEIRO; GARCEZ, 2002). Tanto falante quanto ouvinte são fundamentais na construção das mensagens e dos significados, os cenários e contextos tornam-se relevantes para o entendimento dessas interações, assim como, a forma como os indivíduos se dispõem nessas situações (RIBEIRO; GARCEZ, 2002).

Decorrente de um caráter naturalista/construtivista, a que o artigo está alinhado, utilizou-se de observações participantes, alinhadas à técnica de entrevistas etnográficas para coletar os dados, uma vez que elas permitem entender o que está para além do que foi dito.

A observação participante foi uma técnica de coleta dos dados utilizada, uma vez que esta técnica reposicionou uma das pesquisadoras como membro do grupo observado, compartilhando as experiências de vida, hábitos e convenções sociais (NOVAES; GIL 2009). Por meio desta observação foi possível imergir no campo de análise observando os fenômenos, a partir da perspectiva de ser membro, assim como, influenciando o que estava sendo observado devido as suas participações (FLICK, 2004).

Inicialmente as pesquisas foram voltadas para coleta de dados em ambientes de apresentação do Maracatu Rural, entre ensaios, apresentações no carnaval e conversas com brincantes. Após as fases de identificação dos grupos analisados e da coleta de dados, identificou-se uma insatisfação por parte de alguns agentes públicos, em relação aos resultados das análises dos dados. Por meio deste insight, resolveu-se fazer uma análise comparando o que já havia sido coletado - Maracatu Rural - com a escolha de um brinquedo aleatório, neste caso, os Ursos. A partir daí, buscou-se ler com maior intensidade sobre os Ursos do Carnaval, a fim de identificar, se de fato, as dúvidas 
levantadas pelas pesquisadoras, sobre o processo de distinção e relações de poder eram pertinentes ao objetivo de pesquisa.

\section{ANÁLISE DE DADOS}

O que levou a analisar essa distinção entre os grupos de Maracatus Rurais e Ursos Carnavalescos, foi devido as pesquisas iniciais, realizadas com grupos de Maracatu Rural em que se buscou compreender como estes se comportavam dentro do cenário do carnaval. Observou-se que entre os próprios grupos de maracatus havia alguns que se destacavam em relação aos demais. Analisa-se adiante esse fenômeno à luz da teoria de Bourdieu (2008) como sendo o acúmulo de capitais políticos, econômicos e sociais. Tal fato, levou a inquietação de tentar entender como se dava esse processo de distinção. Entretanto, o ponto crucial para as buscas, foi uma entrevista realizada com o Assessor de Marketing da Secretaria de Turismo do Recife, quando conversou-se com ele sobre as insatisfações dos folgazões de Maracatu, quanto aos investimentos por parte dos Órgãos Públicos nestes brinquedos. $\mathrm{O}$ assessor não gostou de ouvir os comentários e afirmou: "eles - os brincantes - choram muito! Eles querem todo investimento para eles e não veem que têm outros grupos também! Eles são os que mais ganham investimento!". A fala do assessor levou a refletir o porquê desse maior investimento, e então, escolheu-se aleatoriamente, o brinquedo Ursos Carnavalescos para analisar alguns pontos. Fundamentando-se na teoria de Bourdieu (2001), identificou-se na fala do assessor uma mensagem carregada de significados contundentes para análise, inicialmente elencou-se o capital social, que Bourdieu (2012) o explica como sendo as relações sociais que são adquiridas e conservadas ao longo das vidas das pessoas, nesse caso, o capital social para os "maracatuzeiros" estava contribuindo para um melhor relacionamento entre os agentes internos e órgãos públicos responsáveis pelas questões de incentivos culturais. Outro capital observado foi o econômico, uma vez que esse estreitamento na rede de relacionamentos permite que os grupos de maracatus recebessem maior investimento que outros brinquedos, quanto maior a comunicação e influência que ocupavam os folgazões do maracatu em 
setores voltados para cultura e turismo, mais oportunidade de exibição possuíam, e quanto mais investimentos os grupos recebiam, eles investiam na produção do grupo.

Um fator de relevância identificado na pesquisa, diz respeito à existência de Associações. No caso dos Maracatus existia uma Associação para organizar e orientar os grupos em relação as participações nos eventos do carnaval. Os grupos associados, conseguiam facilidades e recebiam investimentos para se apresentar. Esta ação permitiu identificar como estes representantes encaravam a tradição que acreditavam e como valorizavam sua cultura e seus costumes. Analisando este ponto à luz de Bourdieu (2012), o capital social estava se sobressaindo nas relações dos grupos de Maracatus e atrelado a este, identificou-se o capital cultural, que Bourdieu (2012) o define como a bagagem de aprendizados, experiências e tradições das pessoas, tudo que fora passado entre gerações, ou seja, a criação de uma Associação seria uma forma de manter viva a cultura de um povo legitimamente. Sendo assim, mais um capital foi observado fortemente na estrutura dos grupos de maracatus, o capital simbólico, que é trazido por Bourdieu (2012) como a ideia do significado, do valor, do sentimento de pertencimento que determinado objeto, cultura ou pessoa exerce sob uma população, e este capital simbólico foi observado quando identificaram-se os grupos na forte busca de resgatar, preservar e valorizar os seus costumes, através da articulação entre os membros que se protegiam, perpetuando seus valores e costumes por meio das relações entre os integrantes. Nos grupos dos Ursos do Carnaval, não identificou-se um órgão competente pela concentração, articulação e controle dos grupos. A ideia que fora passada às pesquisadoras, é que cada grupo de Ursos, funcionava por conta própria, fato que estava dificultando a articulação e envolvimento com agentes públicos, ou seja, mesmo havendo uma articulação entre os próprios brincantes, esta não estava funcionando de forma forte e concisa a ponto de criar um movimento próprio capaz de buscar melhorias em benefício da causa (aumentar valorização dos Ursos).

Quanto aos grupos de Maracatus, fora observado uma quantidade significativa de grupos existentes. Segundo Henrique (diretor do Maracatu Piaba de Ouro e integrante da Associação de Baque Solto), eram mais de 90 grupos de maracatus cadastrados e regulamentados na Associação. Em contrapartida, contava-se com pouco mais de 11 grupos de Ursos do Carnaval, segundo Fundação Joaquim Nabuco (2014), acarretando dessa forma, na significância de representantes na Programação do 
Concurso do Carnaval do Recife. Para se ter ideia, em números, identificou-se que no Grupo de Acesso das 8 vagas reservadas para os Ursos- La Ursa, apenas 5 grupos se inscreveram; no caso do Grupo II, das 19 vagas para os Maracatus Baque Solto, foram inscritos 20; e das 8 dos Ursos, apenas 7 realizaram a inscrição; no Grupo I, das 17 vagas para Maracatu Rural, 18 se inscreveram e das 8 para Ursos, houve 9 inscritos; e por fim no Grupo das Especiais, das 6 vagas ofertadas para cada grupo - Maracatus e Ursos, todas as vagas foram preenchidas.

Diante de tais evidências, admitiu-se que as vantagens sociais, de fato proporcionaram um acúmulo de capitais, uma vez que a questão do prestígio, do reconhecimento e consequente divulgação, estava dependendo do fato de como, e com quem, os brincantes se articulavam, para daí conseguir algum benefício em relação aos outros. Os grupos de Maracatus conseguiam ter melhor articulação política, além de se venderem melhor com a ideia de cultura genuína. Estando em maior número, ou seja, com mais representatividade no cenário do carnaval, fato que permitia maior visibilidade. Tais pontos proporcionaram aos grupos de Maracatus o aumento dos capitais culturais - pela sua tradicionalidade; capitais simbólicos - pela representação da força do brinquedo entre os demais brinquedos do Estado, tanto que o caboclo de lança, segundo Luna (2013) é considerado símbolo de carnaval do Recife; Capitais sociais devido às várias pessoas de diversos setores que se articulavam buscando incentivos e melhorias para os seus grupos; e por fim, o capital econômico - devido à demanda de investimento destinada a estes grupos. Quanto aos Ursos, a leitura feita sobre sua existência no cenário da cultura popular, é que as conquistas por eles desfrutadas, em relação ao reconhecimento de cultura e tradição decorria do esforço de grupos emblemáticos e significativos como os Maracatus.

\section{CONSIDERAÇÕES FINAIS}

Dentro do contexto apresentado, considerou-se ter ficado claro o quanto os grupos de Ursos - La Ursa, precisavam melhorar, no sentido de se fortalecer, seja também criando uma Associação ou outro órgão que os representassem com uma voz única dentro desse mercado do entretenimento que o carnaval está inserido. Seria 
necessário haver uma articulação que os fortalecessem como estava ocorrendo com os grupos de Maracatu Rurais. Essa unicidade e representatividade dos grupos, estava permitindo que as Instituições (Associações) legitimassem, divulgassem e profissionalizassem o brinquedo, caso estes almejassem divulgação e reconhecimento como cultura influente no Estado. Considerou-se notório que a quantidade de grupos de Maracatus Rurais foi relevantemente maior que as dos Ursos, isso implicando em uma maior visibilidade de um em relação ao outro.

Como a partir de Bourdieu (2012), a legitimação e distinção entre os brinquedos, estava se dando decorrente ao acúmulo de capitais. Os grupos de Maracatus Rural souberam articular e se firmar em um mercado por meio da sábia utilização destes capitais, por exemplo, Mestre Manuel Salu, do Maracatu Piaba de Ouro, tornou-se referência artística no cenário local e por seus contatos no meio da política, conseguiu elevar seu grupo a um alto patamar e influente do Estado, ficando equivalente, se não mais relevante que o Cambinda Brasileira - maracatu de baque solto mais antigo que se tem registro (PREFEITURA DE NAZARÉ DA MATA, 2013). Houve brincante do Piaba de Ouro que afirmou que eles já não concorriam mais nos concursos do Carnaval, porque só faziam ganhar. Sendo assim, Manuel Salu deu oportunidade para outros grupos participarem e concorrerem no concurso também. Outro ponto importante que distinguiu o Maracatu Rural em relação a outros brinquedos, diz respeito a um personagem (o caboclo de lança) do seu cortejo ser reconhecido e legitimado como símbolo do Carnaval da Cidade, tal fato o elevando a uma categoria de maior reconhecimento, seja pelo acúmulo de capitais simbólicos e sociais. Outro ponto que elevava o Maracatu ao nível de reconhecimento e distinção é o fato deste brinquedo fazer parte do circuito de Rotas Turísticas oferecidas pela Secretaria de Turismo (EMPETUR, 2013), assim como, ter uma cidade - Nazaré da Mata - que movimentava sua atividade econômica, entre outras coisas, com o turismo cultural baseado nos Maracatus Rurais (PREFEITURA DE NAZARÉ DA MATA, 2013).

Diante de tantas características que corroboraram para o reconhecimento e distinção dos Maracatus Rurais em relação aos Ursos - La Ursa, deparou-se com uma realidade onde quase não se escutava falar deste brinquedo, e o fato deles não terem grupos suficientes para se apresentarem nos diversos polos oferecidos pela Prefeitura do Recife, dificultando a divulgação deste brinquedo diante de turistas, moradores e até 
curiosos. Como dito anteriormente, seria necessário a articulação e um maior envolvimento. Inclusive na questão das inscrições nos eventos do carnaval do Recife, pois como se pôde observar nos dados apresentados, as vagas reservadas para os grupos de Ursos, nem sempre eram totalmente preenchidas.

Sendo assim, as indagações levaram a concluir que de fato, havia uma distinção entre os brinquedos Maracatu Rural e Ursos - La Ursa, e que esta distinção não se dava por uma questão de tradicionalidade ou essência cultural por parte dos brinquedos, muito pelo contrário, o que identificou-se foi uma organização voltada para questões comerciais muito mais estruturada por parte dos Maracatus, do que as que funcionavam individualmente por parte dos Ursos. Ambas atendendo o mercado do carnaval, caso contrário, não seriam capazes de desfilar nos Concursos, o que faltaria de fato, era os grupos dos Ursos, se profissionalizarem trançando metas mais ousadas.

\section{REFERÊNCIAS}

BARACHINHA. Histórias do maracatu. Parque dos lanceiros. Nazaré da Mata, 22 de jan. 2013. Entrevista.

BAUDRILLARD, J. A Sociedade do Consumo. Lisboa: Edições 70, LDA, 2005.

BONAMINO, A.; ALVES, F.; FRANCO, C. Os efeitos das diferentes formas de capital no desempenho escolar: um estudo à luz de Bourdieu e de Coleman. Revista Brasileira de Educação, v. 15, n. 45, set./dez. 2010.

BONNEWITZ, P. Primeiras Lições sobre a Sociologia de Pierre Bourdieu. Petropólis: Editora Vozes, 2003.

BOURDIEU, P. A Distinção: crítica social do julgamento; tradução Daniela Kern; Guilherme J. F. Teixeira. São Paulo: Edusp; Porto Alegre, RS: Zouk, 2008.

A economia das trocas simbólicas: introdução, organização e seleção Sérgio Miceli. 7. ed. São Paulo: Perspectiva, 2011.

A formação do habitus econômico (tradução de "Making the economic habitus) Algerian workers revisited”. Ethnography, v. 1, n. 1: 17-41, junho, 2000). 
O poder simbólico; tradução Fernando Tomaz. 16. ed. Rio de Janeiro: Bertrand Brasil, 2012.

. "O campo econômico". Revista Política \& Sociedade, UFSC, v. 4, n. 6, p. 1557, abril. 2005.

As estruturas sociais da economia. Lisboa: Instituto Piaget, 2001.

EMPETUR - Empresa de Turismo de Pernambuco. Disponível em: <http://www.pe.gov.br/conheca/turismo/>. Acesso em: 15/08/2013.

FLICK, U. Uma introdução à pesquisa qualitativa. 2. ed. Porto Alegre: Bookman, 2004.

FUNDAÇÃO JOAQUIM NABUCO. Disponível em:

$<$ http://basilio.fundaj.gov.br/pesquisaescolar/index.php?option=com_content\&view $=$ arti cle\&id=576\%3 Acarnaval-no-nordeste-do-brasil\&catid=37\%3Aletra-b\&Itemid=1 > .

Acesso em: 24/10/2014.

Disponível em:

$<$ http://basilio.fundaj.gov.br/pesquisaescolar/index.php?option=com_content\&view=arti cle\&id=753:ursos-do-carnaval\&catid=55:letra-u\&Itemid=1>. Acesso em: 24/10/2014.

GARCIA-PARPET, M. "A gênese social do homo-economicus: a Argélia e a sociologia da economia em Pierre p Bourdieu". Mana, Rio de Janeiro, v.12, n. 2, p. 333-357, out. 2006.

. "A sociologia da economia de Pierre Bourdieu". Sociologia\&Antropologia,

Rio de Janeiro, v. 3, n. 5, p. 91-117, junho de 2013.

GAY, P. do.; PRYKE, M. Cultural Economy: cultural analysis and commercial life. London: Sage publications, 2002.

GOFFMAN, E. The neglected Situation. American Anthropologist. Berkeley, 1964, p. 133-166.

GRILLO, M. Cavalo-marinho: um folguedo Pernambucano. Revista Esboços, Florianópolis, v. 18, n. 26, p. 138-152, dez. 2011.

HALL, S. "The work of representation". In: HALL, S. (Org.) Representation. Cultural representation and cultural signifying practices. London/Thousand Oask/ News Delhi: Sage/ Open University, 1997, p. 1- 47. 
LIMA, A. Tradição do Maracatu. Ensaio do Maracatu Leãozinho de Aliança. Aliança. 12 de jan. 2013. Entrevista.

LÓSSIO, R.; PEREIRA, C. História e Estórias do Carnaval em Pernambuco. Recife: Fundação Joaquim Nabuco, 2008.

LUNA, A. Mercantilização dos maracatus. Ensaio do Leãozinho de Aliança. Aliança. 12 de jan. 2013. Entrevista.

MAUSS, M. Sociologia e antropologia. São Paulo: Cosac Naify, 2002.

MOM - MORAR DE OUTRAS MANEIRAS. Disponível em: <http://www.mom.arq.ufmg.br/mom/05_biblioteca/acervo/morado_info.pdf $>$. Acesso em: 15/08/2013.

NOVAES, M.; GIL, A. A pesquisa-ação participante como estratégia metodológica para o estudo do empreendedorismo social em administração de empresas. RAM - Revista de Administração Mackenzie, v. 10, n. 1, 2009.

O ESTADÃO DE SÃO PAULO. Disponível em:

<http://www.estadao.com.br/noticias/impresso,maracatu-de-baque-solto-se-multiplicaolinda-faz-encontro-anual,511871,0.htm>. Acesso em: 15/05/2012.

PEREIRA, D. Regras Concurso Carnaval do Recife. Pólo Avenida do Forte, Recife 12 de fev. de 2013. Entrevista.

PREFEITURA DA CIDADE DE NAZARÉ DA MATA. Disponível em: <http://www.nazaredamata.pe.gov.br/nazare/index.php/maracatu>. Acesso em: 15/08/2013.

RAUD, C. "Bourdieu e a nova sociologia econômica". Tempo Social, revista de sociologia da USP, v. 19, n. 2, p. 202-232, novembro, 2007.

RETONDAR, A. Sociedade de consumo, modernidade e globalização. São Paulo: Annablume; Campina Grande: EDUFCG, 2007.

RIBEIRO, B.; GARCEZ, P. Sociolinguística Interacional: humanística. São Paulo: Edições Loyola, 2002.

SHINOHARA, N.; MARTINS, C.; OLIVEIRA, K.; PADILHA, M.; PINTO, I. O bolo Souza Leão: Pernambuco dos sabores culturais. Revista Contexto da Alimentação: Comportamento, Cultura e Sociedade, v. 2, n. 1, 2013. 
SILVA, E. Índios organizados, mobilizados e atuantes: história indígena em Pernambuco nos documentos do Arquivo Público. Revista de Estudos e Pesquisas, FUNAI, Brasília, v. 3, n. 1/2, p. 175-224, jul./dez. 2006.

SILVA, S. Culturas do Açúcar em Pernambuco. CLIO - Série Revista de Pesquisa Histórica, n. 26-2, p. 95-110, 2008.

Festa do Caboclo. 2. ed. Revista e Ampliada. Olinda, PE: Associação Reviva, 2012.

WACQUANT, L. J. D. O legado sociológico de Pierre Bourdieu: Duas dimensões e uma nota pessoal. Revista Sociologia Política, Curitiba, 19, p. 95-110, nov. 2002.

Recebido em: 19-07-2016.

Aprovado em: 18-08-2016. 